Journal of Experimental Social Psychology

Journal of Experimental Social Psychology 44 (2008) 699-705

www.elsevier.com/locate/jesp

\title{
Not fair for me! The influence of personal relevance on social justice inferences is
}

\author{
Jaap Ham *, Kees van den Bos \\ Department of Social and Organizational Psychology, Utrecht University, The Netherlands
}

Received 5 July 2006; revised 14 March 2007

Available online 30 April 2007

\begin{abstract}
In this paper, we argue that the personal relevance of a situation primarily influences spontaneous inferences about social justice, and not necessarily affects explicit justice judgments. To test this hypothesis, two studies manipulated personal relevance and assessed justice inferences and judgments: Participants read descriptions of fair or unfair events happening to stimulus persons referred to with first-person versus third-person pronouns (Experiment 1) or as "a friend" versus "a stranger" (Experiment 2). We then measured spontaneous justice inferences (using the probe recognition paradigm) and explicit justice judgments (using rating scales). As predicted, both studies showed stronger spontaneous justice inferences for high personal relevance descriptions, of unjust events specifically, whereas explicit justice judgments were not significantly influenced by our personal relevance manipulations. These findings suggest that especially the spontaneous component of the justice judgment process is sensitive to personal relevance.
\end{abstract}

(C) 2007 Elsevier Inc. All rights reserved.

Keywords: Justice; Morality; Personal relevance; Spontaneous inferences; Explicit judgments

Imagine that you and your colleague do the same work, but that you only make 1400 Euros whereas your colleague makes 4100 Euros a month. Now imagine the same situation, but this time with low personal relevance: Not you, but somebody else earns less money than a colleague for the same amount of work. How would your assessment of the justice of the situation be influenced by whether the situation occurs to you or to somebody else? In other words, how would the social-cognitive processes of justice judgments be influenced by personal relevance?

Research evidence suggests that people interpret events egocentrically (see, e.g., Gilbert \& Gill, 2000; Gilovich \& Savitsky, 1999; Ross, Green, \& House, 1977) and that especially people's spontaneous reactions are influenced by egocentric biases (e.g., Epley, Kaysar, Van Boven, \& Gilovich, 2004; Kruger, 1999). For example, most people think they

\footnotetext{
This research was supported by a VICI Grant (NWO-453.03.603).

* Corresponding author.

E-mail address: J.R.C.Ham@uu.nl (J. Ham).
}

drive a car better than average, especially when making their judgments under cognitive load and thereby giving less controlled reactions (Kruger, 1999). In contrast, people's more controlled and explicit reactions to events are less egocentrically biased and more objective (Epley et al., 2004).

In the current paper, we argue that the personal relevance of a situation primarily influences spontaneous reactions in moral and justice judgments, and not necessarily explicit justice judgments. This assumption is in line with theorizing by Haidt (2001), who argued that moral judgments are generally the result of quick, spontaneous processes, that include subjective, affective valence evaluations (e.g., "like" vs. "dislike"). More specifically, we propose that these "egocentric ethics" (Epley \& Caruso, 2004) often are caused by spontaneous, egocentric characteristics of human judgment whereas people's explicit justice judgments show less strong effects of factors associated with personal relevance. This proposition, to be found in the modern literature on justice and morality (e.g., Epley \& Caruso, 2004; Haidt, 2001), has never been 
directly empirically investigated, as the above-mentioned theorists acknowledge.

We propose here that people will spontaneously think about justice in especially strong ways when a highly personally relevant justice-implying event happens (e.g., to themselves or to a friend, as opposed to someone else, such as a stranger), and we predict that these effects will be particularly strong for unjust-implying events. This proposition is based on previous research which indicates that people spontaneously assess aspects of the environment that are relevant for them personally (Epley et al., 2004; Gilbert \& Gill, 2000; Nickerson, 1999) and that unjust events affect people's reactions more strongly than just events do (Folger, 1984). Furthermore, in line with Epley et al. (2004), we argue that people will be less sensitive to injustices experienced by others.

In the current research, we will directly test these predictions. Importantly, earlier research (assessing explicit justice judgments) sometimes found effects of personal relevance and perspective taking on moral and justice judgments (e.g., Epley \& Dunning, 2000; Messick \& Sentis, 1983), whereas other studies could not replicate such an effect (e.g., Finkel, 2001; Huo, Smith, Tyler, \& Lind, 1996). Finding evidence for effects of personal relevance on especially spontaneous justice inferences (and more so than on explicit justice ratings) would advance our field and would suggest on what types of cognitive processes and type of dependent variables effects of personal relevance are most likely to be found.

\section{Overview}

We performed two studies to investigate the influence of personal relevance on spontaneous justice inferences and on explicit justice judgments. In both studies, we assessed spontaneous justice inferences and explicit justice judgments that people made about justice-relevant descriptions of different levels of personal relevance. When assessing spontaneous justice inferences and making explicit justice judgments, participants saw the same short situation descriptions in which a stimulus person was treated in fair or unfair ways. Half of these descriptions portrayed a stimulus person of high personal relevance, and half a stimulus person of low personal relevance.

In Experiment 1, situation descriptions of high personal relevance described a stimulus person by using first-person pronouns (e.g., a description of a just-implying event was: "You and your colleague do the same work. You make 1400 Euros a month and your colleague makes 1400 Euros a month"). Situation descriptions of low personal relevance described a stimulus person by using third-person pronouns (e.g., a description of an unjust-implying event was: "He and his colleague do the same work. He makes 1400 Euros a month and his colleague makes 4100 Euros a month"). In Experiment 2, personal relevance was manipulated by presenting the stimulus person either as a friend or as a stranger.
We assessed participants' spontaneous justice inferences by means of the probe recognition paradigm (McKoon \& Ratcliff, 1986). This paradigm has been used successfully in earlier studies to examine activation of various types of spontaneous inferences, for example the activation of spontaneous trait inferences (Uleman, Hon, Roman, \& Moskowitz, 1996). We measured participants' explicit justice judgments by means of rating scales that are commonly used in justice studies (Lind \& Tyler, 1988).

Our predictions were that we would find effects on the probe recognition measures indicating that participants draw justice inferences spontaneously when they read the descriptions that implied just or unjust events. Second, we expected stronger spontaneous justice inferences for situation descriptions of high personal relevance than for situation descriptions of low personal relevance. Third, we expected stronger spontaneous justice inferences for situation descriptions of high personal relevance that implied unjust events (cf. Folger, 1984). Fourth, we expected that participants' explicit justice judgments would be dependent on the just-versus unjust-implications of our descriptions, but less likely to show strong effects of the personal relevance manipulation than our probe recognition data.

\section{Experiment 1}

\section{Method}

\section{Participants and design}

Participants were 154 students (48 men and 106 women $)^{1}$ at Utrecht University. For their participation of $20 \mathrm{~min}$ they received 2 Euros. The design of Experiment 1 was a 2 (trial type: experimental vs. control) $\times 2$ (description type: just-implying vs. unjust-implying) $\times 2$ (stimulus person: first vs. third-person pronouns) within-subjects design.

\section{The probe recognition paradigm}

Participants read a short description of a situation after which a probe word was presented on their screens. Participants were asked to accurately indicate as quickly as possible whether this probe word was part of the sentence they read. For example, participants in our experimental trials read the sentence "You and your colleague do the same work. You make 1400 Euros a month, and you colleague 4100 Euros", while on control trials they read a sentence that used the same words (including identical pronouns to refer to the actor) but which did not imply anything related to social justice. After such a sentence had been presented, the word "just" was presented on participants' computer screen and participants were asked to indicate whether this probe word was part of the sentence they had read. If justice inferences are spontaneously drawn

\footnotetext{
${ }^{1}$ In both our experiments, gender showed no effects on our dependent variables, all $F_{\mathrm{s}}<1$.
} 
while reading the experimental description, then we should find that participants need more time to respond and/or more often respond incorrectly on experimental trials as compared to control trials (the probe recognition effect). This is because the spontaneous justice inference might have interfered with correctly and quickly rejecting the probe word after reading a description that did imply that probe word more so than after reading a description that did not (McKoon \& Ratcliff, 1986). Thereby, finding the probe recognition effect indicates that participants spontaneously drew justice inferences.

\section{Stimulus materials}

In the probe recognition paradigm, participants completed 60 trials in random order. In each trial, a short description and a single probe word were presented to the participants. Of the 60 trials, 8 trials (4 experimental and 4 control trials) were the critical trials that were used to test our hypotheses.

In the 4 experimental trials, each description was succeeded by a probe word that was implied by the description. Two experimental trials employed a high personal relevance description, whereas the other 2 experimental trials employed a low personal relevance description, as in the examples presented earlier. In both these 2 sets of 2 experimental trials, the description implied a just event in one trial, and an unjust event in the other trial (e.g., a description of a just [unjust] event was: "On the first class, the professor states that 2 [1] of 2 assignments must be handed in. After the course, both assignments are used to calculate your grade"). Some of the four experimental descriptions involved distributive justice, some procedural justice. (All descriptions can be found in the appendix of Ham \& Van den Bos, submitted for publication, and are available on request.)

The 4 control trials were similar to the 4 experimental trials, but these descriptions presented the words in a different order such that these control descriptions formed logical sentences that did not imply anything related to social justice.

Probe words on the 4 experimental and 4 control trials were taken from a set of 8 words related to social justice. As just probe words we used the Dutch words for "just", "fair", "justified", and "appropriate" and, as unjust probe words, "unjust", "unfair", "unjustified", and "inappropriate". For all trials, at random a description and a concurring probe were chosen with this restriction that no 2 trials used the same materials.

In addition to the 8 critical trials, 52 filler trials unrelated to social justice were included in the experiment for two reasons. First, if all materials would be only justicerelated, we would not be able to show that it is specifically spontaneity of justice inferences (as opposed to other, more general inferences) that we are revealing here (McKoon \& Ratcliff, 1986). Second, if all correct responses would only be to answer "no", spending attention to the description would not be necessary to complete the task (McKoon \&
Ratcliff, 1986). Therefore, in 30 of the 52 filler trials the probe was a word that was literally in the description. Filler descriptions and probe words were comparable in length and sentence structure to the critical descriptions and probe words.

\section{Experimental procedure}

The experiment was run on a computer and started with an explanation of the first task. The first task was the probe recognition task which started with a practice round of 12 trials. The practice rounds were the same as the trials of the experimental task, but materials were unrelated to social justice. Next, the 60 trials of the main task started. In each trial, first a row of X's appeared in the middle of the screen for $1000 \mathrm{msec}$. Next, the description was displayed for $3000 \mathrm{msec}$, followed by a blank screen lasting $500 \mathrm{msec}$. Again a row of X's appeared on screen for $500 \mathrm{msec}$, this time followed by the probe. During the whole task the words "yes" and "no" remained visible on the right and left side of the screen. From the moment the probe was presented, participants could press the appropriate keys (the "a"-key, respectively, "6"-key to indicate "no", respectively, "yes") to give their answer. The probe remained visible until the participant had pressed one of both keys. After the answer was given, a blank screen was displayed for $1000 \mathrm{msec}$. Then, the next trial started.

For the explicit measurement of justice judgments the short descriptions of the 8 critical trials were again presented and participants were asked to evaluate how just $(1=$ very unjust, $7=$ very just $)$, fair $(1=$ very unfair, $7=$ very fair $)$, appropriate $(1=$ very inappropriate, $7=$ very appropriate $)$, and justified $(1=$ very unjustified, $7=$ very justified) the event described was. For each of the four different kinds of descriptions (2 description types [just-implying vs. unjust-implying] $\times 2$ stimulus persons [first vs. third-person pronouns]), participant's answers were averaged to form a reliable scale of their justice judgments (alpha's > .86). After this, participants were thanked, paid for their participation, and debriefed.

\section{Results and discussion}

\section{Probe recognition paradigm}

Both when analyzing response times and error rates, we found evidence supporting our hypotheses. Below, we present our analysis of response times. ${ }^{2}$ Response time data of 14 participants could not be analyzed because they gave incorrect answers on critical trials. Following Ratcliff (1993), we analyzed our response latencies data by using two methods: an absolute cutoff criterion of $<200 \mathrm{~ms}$ and $>2000 \mathrm{~ms}$, and an inverse transformation $(1 / \mathrm{x})$ of the response latencies. The analyses reported hereafter are based on the cutoff criterion, which yielded converging

\footnotetext{
${ }^{2}$ In both our experiments, analyses of error rates showed results identical to the response times data. To be concise, error rates results will not be discussed here and are available on request.
} 
results to the inverse transformation analysis. Because of the cutoff criterion, the response time data of another 8 participants were dropped, leaving 132 participants in our data set.

Response times were submitted to a 2 (trial type: experimental vs. control) $\times 2$ (description type: just-implying vs. unjust-implying) $\times 2$ (stimulus persons: first-person vs. third-person pronouns) ANOVA. Mean response times are presented in Table 1. Replicating earlier findings (Ham \& Van den Bos, submitted for publication), results suggest spontaneous justice inferences. That is, as predicted, participants responded slower on experimental trials $(M=737, S D=116)$ than on control trials $(M=682$, $S D=152)$, indicated by a main effect of trial type, $F(1,131)=43.51, p<.001$. So, as expected, participants were slower in rejecting (justice-related) probe words on experimental trials (after reading a description that implied a just or unjust event) than on a control trials (after reading a justice-unrelated control description). This probe recognition effect indicates that while reading the description, justice inferences were spontaneously drawn and that the justice knowledge that was thus activated interfered with quickly rejecting the probe word, thereby supporting our first hypothesis.

Our second hypothesis was also supported: As predicted, the main effect of trial type (the probe recognition effect) was qualified by the two-way interaction of Trial Type $\times$ Stimulus Persons, $F(1,131)=5.92, p<.05$. When the stimulus person of the description was referred to with first-person pronouns, the probe recognition effect was strongest and participants responded slower on experimental trials $(M=752, S D=93)$ than on control trials $(M=681, \quad S D=158), \quad F(1,131)=41.63, \quad p<.001$, $\eta^{2}=.24$. When the stimulus person of the description was referred to by third-person pronouns, the probe recognition effect was also present, but here participants showed a significantly smaller probe recognition effect, though still responding slower on experimental trials $(M=720$, $S D=140)$ than on control trials $(M=682, S D=147)$, $F(1,131)=13.04, p<.001, \eta^{2}=.09$.

Our third hypothesis was that the strongest spontaneous justice inferences would be found for first-person descriptions that implied an unjust event. Again, results supported our predictions: The probe recognition effect (the main

Table 1

Mean critical response times (and standard deviations) by Trial Type, Description, and Stimulus Person (Experiment 1)

\begin{tabular}{lccccc}
\hline & \multicolumn{4}{c}{ Stimulus person } \\
\cline { 2 - 3 } \cline { 5 - 6 } \cline { 5 - 6 } Description & $\begin{array}{c}\text { Experimental } \\
\text { trial }\end{array}$ & $\begin{array}{c}\text { Control } \\
\text { trial }\end{array}$ & & $\begin{array}{c}\text { Experimental } \\
\text { trial }\end{array}$ & $\begin{array}{c}\text { Control } \\
\text { trial }\end{array}$ \\
\cline { 2 - 3 } $\begin{array}{c}\text { Just- } \\
\begin{array}{c}\text { implying } \\
\text { Unjust- } \\
\text { implying }\end{array}\end{array}$ & $724(134)$ & $678(143)$ & $736(94)$ & $687(143)$ \\
\hline
\end{tabular}

effect of trial type) was qualified by the three-way interaction of Trial Type $\times$ Stimulus Persons $\times$ Description Type, $F(1,131)=4.10, p<.05$. Follow-up analyses indicated that when the stimulus person of the description was referred to by first-person pronouns, results showed an interaction of Trial Type $\times$ Description Type, $F(1,131)=6.31, p<.05$, $\eta^{2}=.05$. This indicated that when the stimulus person of the description was referred to by first-person pronouns and the description had implied an unjust event, the probe recognition effect (a response time of $M=768, S D=91$ on experimental vs. $M=673, S D=171$ on control trials) was larger, $F(1,131)=38.35, p<.001, \eta^{2}=.23$, than when the stimulus person of the description was referred to by first-person pronouns and the description had implied a just event $(M=736, S D=94$ vs. $M=687, S D=143)$, $F(1,131)=12.94, p<.001, \eta^{2}=.09$. However, when the stimulus person of the description had been referred to by third-person pronouns, an interaction of Trial Type $\times$ Description Type was not found, $F<1, \eta^{2}=.01$, which suggests that for low personally relevant descriptions the probe recognition effect was not influenced by whether the descriptions implied unjust or just events.

Results indicated no statistical reliable evidence that descriptions implying just events led to different probe recognition effects than descriptions implying unjust events, as indicated by a non-significant interaction between trial type and description type, $F(1,131)=1.66, p>.20$. Another interesting finding is that when the stimulus person of a descriptions was referred to by first-person pronouns $(M=717, S D=125)$, participants showed slower overall response times than when the stimulus person of a descriptions was referred to by third-person pronouns $(M=702$, $S D=144), F(1,131)=4.01, p<.05$. So, stimulus materials of stronger personal relevance led to slower response times. However, this effect did not interact with trial type and, therefore, is less central to our current purposes.

\section{Explicit justice judgments}

In line with our fourth hypothesis, a $2 \times 2 \times 2$ ANOVA on participants' explicit justice judgments indicated that participants rated descriptions that implied a just event as more just than descriptions that implied an unjust event, $F(1,153)=527, p<.001$. In contrast to the probe recognition findings, this effect was independent of whether the stimulus person of the description was referred to by first-person or third-person pronouns, all $F \mathrm{~s}<1$. In line with expectations, justice judgments showed an interaction of Trial Type $\times$ Description Type, $F(1,153)=573.77$, $p<.001$. As expected, experimental descriptions that implied a just event were rated as more just $(M=6.3$, $S D=1.3)$ than experimental descriptions that implied an unjust event $(M=1.5, \quad S D=0.9), \quad F(1,153)=114.6$, $p<.001, \eta^{2}=.43$. For control descriptions, this effect was not found $(M=4.7, S D=2.0), p>.28, \eta^{2}<.01$, which was not surprising because these descriptions had been designed and pretested not to imply anything related to social justice. 
Relationship between spontaneous inferences and explicit judgments

Results indicated no overall or within-cell correlations between participants' spontaneous justice inferences (neither when based on response times nor when based on error rates) and explicit justice judgments, all $r \mathrm{~s}<.08$, all $p \mathrm{~s}>.36$.

\section{Experiment 2}

\section{Method}

\section{Participants}

Participants were 113 students (45 men and 68 women) at Utrecht University. For their participation of $20 \mathrm{~min}$ they received 2 Euros.

\section{Stimulus materials, design, and procedure}

Experiment 2 was identical to Experiment 1, except for three changes. First, in the high personal relevance trials the stimulus person was now referred to as "a friend" and in the low personal relevance trials as "a stranger". Second, we included a just vs. unjust probe type manipulation in our probe recognition task. To this end, Experiment 2 used 16 critical trials ( 8 experimental and 8 control trials) to be able to investigate whether in our probe recognition paradigm activation of just-related probe words might be distinguished from activation of unjust-related probe words. As in Experiment 1, half of the experimental trials used just probe words and the other half used unjust probe words. Different from Experiment 1, each description was used twice: once with a just probe word and once with an unjust probe word. Third, because of the higher amount of critical trials, the current experiment used 44 of the 52 filler trials of Experiment 1. Again, for the second task, participant's answers to the three explicit justice judgment questions were averaged to form reliable scales of their justice judgments for each type of descriptions (alpha's $>.81$ ).

\section{Results}

\section{Probe recognition task}

An analysis of response times (using the same procedures as in Experiment 1) fully supported our hypotheses. As in Experiment 1, all participants had a low error rate ( $M=4.45 \%$, ranging from $0 \%$ to $31.0 \%$ ). Following the restrictions described in Experiment 1, the response time data of 11 participants had to be dropped (6 because of wrong answers and 5 because of too fast or too slow response times) and 102 participants were entered into the analyses.

Response times were submitted to a 2 (trial type: experimental vs. control) $\times 2$ (probe word: just vs. unjust $) \times 2$ (description type: just-implying vs. unjust-implying) $\times 2$ (stimulus person: friend vs. stranger) ANOVA. Mean response times are presented in Table 2. In support of our first hypothesis, results suggest participants drew spontaneous justice inferences while reading a description about a friend or about a stranger. That is, we again found the probe recognition effect: Participants responded slower in correctly rejecting probe words on experimental trials $(M=791, S D=118)$ than on control trials $(M=716$, $S D=90$ ), indicated by a main effect of trial type, $F(1,101)=291.16, p<.001$.

In support of our second hypothesis, we found that when the description was about a friend, results showed stronger spontaneous justice inferences indicated by a stronger probe recognition effect $(M=803, S D=115$ on experimental vs. $M=714, S D=88$ on control trials), $F(1,101)=240.57, \quad p<.001, \quad \eta^{2}=.70$, than when the description was about a stranger $(M=779, S D=121$ vs. $M=720, S D=93), F(1,101)=95.42, p<.001, \eta^{2}=.49$, indicated by an interaction of Trial Type $\times$ Stimulus Person, $F(1,101)=18.80, p<.05$.

Our third hypothesis was also supported: Results indicated strongest spontaneous justice inferences for high personally relevant descriptions that implied an unjust event, indicated by an interaction of Trial Type $\times$ Stimulus Person $\times$ Description Type, $F(1,101)=7.07, p<.05$. That is, only for descriptions about a friend, the probe recognition effect was stronger for descriptions of unjust events $(M=815, \quad S D=110 \quad$ vs. $\quad M=711, \quad S D=86)$, $F(1,101)=207.06, p<.00, \eta^{2}=.67$, than for descriptions of just events $(M=792, \quad S D=120$ vs. $M=717$, $S D=91), F(1,101)=91.95, p<.001, \eta^{2}=.48$, indicated by an interaction of Trial Type $\times$ Description Type, $F(1,101)=14.35, p<.05, \eta^{2}=.12$. For descriptions about a stranger, this interaction of Trial Type $\times$ Description Type was not found, $F<1$, indicating no differences between probe recognition effects for descriptions of just or unjust events when these events happened to a stranger.

Extending on Experiment 1, results also suggested that descriptions implying an unjust event caused stronger

Table 2

Mean critical response times (and standard deviations) by Trial Type, Description, stimulus person, and probe word (Experiment 2)

\begin{tabular}{|c|c|c|c|c|c|c|c|c|}
\hline \multirow[b]{4}{*}{ Description } & \multicolumn{8}{|c|}{ Stimulus person } \\
\hline & \multicolumn{4}{|c|}{ Stranger } & \multicolumn{4}{|c|}{ Friend } \\
\hline & \multicolumn{2}{|c|}{ Just-related probe word } & \multicolumn{2}{|c|}{ Unjust-related probe word } & \multicolumn{2}{|c|}{ Just-related probe word } & \multicolumn{2}{|c|}{ Unjust-related probe word } \\
\hline & $\begin{array}{c}\text { Experimental } \\
\text { trial }\end{array}$ & $\begin{array}{c}\text { Control } \\
\text { trial }\end{array}$ & $\begin{array}{l}\text { Experimental } \\
\text { trial }\end{array}$ & $\begin{array}{c}\text { Control } \\
\text { trial }\end{array}$ & $\begin{array}{c}\text { Experimental } \\
\text { trial }\end{array}$ & $\begin{array}{c}\text { Control } \\
\text { trial }\end{array}$ & $\begin{array}{c}\text { Experimental } \\
\text { trial }\end{array}$ & $\begin{array}{c}\text { Control } \\
\text { trial }\end{array}$ \\
\hline Just-implying & $779(108)$ & $729(101)$ & $782(135)$ & $710(81)$ & $800(126)$ & $717(84)$ & $784(114)$ & $717(98)$ \\
\hline Unjust-implying & 774 (114) & $725(101)$ & 779 (126) & 714 (87) & 843 (116) & 715 (90) & 805 (104) & 707 (79) \\
\hline
\end{tabular}


spontaneous justice inferences than descriptions implying a just event, as indicated by an interaction of Trial Type $\times$ Description Type, $F(1,101)=5.77, p<.05$. Specifically, on experimental trials using a description of an unjust event, participants responded slower $(M=796, S D=115)$ than on experimental trials using a description of a just event $(M=786, S D=121), \quad F(1,101)=5.33, \quad p<.05$, $\eta^{2}=.05$, whereas on control trials, this difference was not found, $F<1$. Although not found in Experiment 1, this finding fits with social cognition findings that negative information draws more attention than positive information (e.g., Dijksterhuis \& Aarts, 2003).

Results further indicated that when the description of a trial had been about a friend, participants responded slower overall than when the description had been about a stranger, $F(1,101)=8.27, p<.01$. Also, although we found no interaction effects including the probe word manipulation, all $F \mathrm{~s}<1$, participants responded slower overall to just-related probe words than to unjust-related probe words, $F(1,101)=5.59, p<.05$.

\section{Explicit justice judgments}

As in Experiment 1, and in corroboration with our fourth hypothesis, participants' explicit justice judgments indicated that descriptions that implied a just event were rated as more just $(M=6.4, S D=1.1)$ than descriptions that implied an unjust event $(M=1.6, S D=1.0)$, whereas for control descriptions this effect was not found, as indicated by a Trial Type $\times$ Description Type effect, $F(1,112)=442.84, p<.001$. However, similar to Experiment 1 , there was no significant effect of whether the stimulus person was a friend or a stranger, all $F \mathrm{~s}<1$.

\section{Relationship between spontaneous inferences and explicit judgments}

As in Experiment 1, results indicated no overall or within-cell correlations between participants' spontaneous justice inferences (neither response times nor error rates) and explicit justice judgments, all $r \mathrm{~s}<.13$, all $p \mathrm{~s}>.16$.

\section{General discussion}

The results of both experiments presented here show an influence of personal relevance on spontaneous justice inferences, and less so (in fact in both our experiments not significantly) on explicit justice judgments. The current results indicate that people draw stronger spontaneous justice inferences (indicated by greater interference effects in a probe recognition paradigm) when confronted with situation descriptions of justice-implying events happening to themselves than to somebody else (Experiment 1) and to a friend than to a stranger (Experiment 2). Thus, we now have evidence that a personally relevant justice-relevant event leads to the strongest spontaneous justice inferences. These results constitute the first empirical evidence of the influence of personal relevance on the social-cognitive processes of spontaneous justice inferences.
Importantly, for descriptions using first-person pronouns or descriptions about a friend, we found that especially unjust events caused the strongest spontaneous justice inferences. For descriptions using third-person pronouns or descriptions about a stranger, spontaneous justice inferences were activated equally strongly for descriptions that implied a just or an unjust event. This result fits with suggestions that especially experiences of unjust events strongly affect people (Folger, 1984) and is in line with the finding that people have different neurological reactions to moral transgressions that happen to themselves versus to someone else (Berthoz, Grezes, Armony, Passingham, \& Dolan, 2006).

In contrast with the strong, reliable effects of personal relevance on spontaneous justice inferences, in both experiments we found that explicit justice judgments showed no statistically significant influence of personal relevance: Participants correctly indicated on 7-point rating scales whether descriptions implied just or unjust events, but whether the event was described from a first-person or third-person perspective (Experiment 1) or whether the stimulus person was a friend or a stranger (Experiment 2) did not influence participants' explicit justice judgments. Thus, both our experiments corroborate the assumption that explicit justice judgments are influenced less by personal relevance than spontaneous responses. This is not to say that personal relevance may never influence explicit justice judgments (Epley et al., 2004). The explicit measures we used here were not exhaustive. Perhaps using other measures (such as affective reactions to just and unjust events and measuring concerns for justice evaluation) and/or assessing justice judgments under high cognitive load (Kruger, 1999) sometimes may lead to more sensitive measures than the traditional assessment of explicit justice judgments we used here.

The current results corroborate and extend earlier assumptions described in the literature (e.g., Epley \& Caruso, 2004; Haidt, 2001). Furthermore, unlike earlier research (e.g., Epley et al., 2004; Kruger, 1999; Loewenstein, Issacharoff, Camerer, \& Babcock, 1993), we tested this assumption such that no extensive description of personal relevance was necessary. Thereby, we introduced a very subtle manipulation of personal relevance to the literature that may be conducive when conducting future research on this important subject.

The current results open interesting avenues for future research about the dynamics of the specific social-cognitive processes involved. This includes potentially very important differences between spontaneous justice inferences and explicit justice judgments. Specifically, it may be the case that our implicit measures tapped process-related aspects of justice judgments (such as the degree to which justice concerns are activated spontaneously), but that the explicit justice judgments tapped content-related aspects of justice judgments (especially the degree to which events were just or unjust). This may imply that our implicit measure assessed whether justice concerns were activated spontaneously, independent of the justice judgment that ultimately (and explicitly) was made. 
The current research also may have implications for the concepts of automaticity and spontaneous justice inferences. Because of the features of the currently used probe recognition paradigm, we know that spontaneous justice inferences share (at least) the feature of spontaneity (unintentionality) and the feature of uncontrollability with automatic processes (see also De Houwer \& Moors, 2007). In the probe recognition paradigm, participants must suppress drawing spontaneous inferences to respond quickly and correctly as instructed. Thereby, this paradigm provides strong evidence that inferring the probe concepts is not only unintended but also difficult to control (Uleman et al., 1996). Earlier research using various research paradigms (Uleman, 1999) showed that spontaneous trait inferences almost completely fit Bargh's (1994) four criteria for automaticity: They are drawn without awareness, unintentionally, are highly efficient, and cannot easily be controlled (Uleman, 1999). Future research is needed to investigate all features of the possible automatic processes of drawing justice inferences.

To return to the example which with we started our paper: If you hear that someone makes less money than a colleague for the same work, the current research indicates that it matters for social-cognitive justice judgment processes whether that someone is you yourself or somebody else. Chances are that when you encounter a situation in which a just or an unjust event happens to somebody, you will spontaneously draw inferences about social justice. However, if something is "not fair for me!" (Finkel, 2001), people draw spontaneous justice inferences stronger than when a situation is "not fair for someone else" or when the situation is "fair for me", though this bias need not show on people's explicit justice judgments.

\section{References}

Bargh, J. A. (1994). The four horsemen of automaticity: Awareness, efficiency, intention, and control in social cognition. In R. S. Wyer, Jr. \& T. K. Srull (Eds.), Handbook of social cognition (2nd ed., pp. 1-40). Hillsdale, NJ: Erlbaum.

Berthoz, S., Grezes, J., Armony, J. L., Passingham, R. E., \& Dolan, R. J. (2006). Affective response to one's own moral violations. NeuroImage, $31,945-950$.

De Houwer, J., \& Moors, A. (2007). How to define and examine the implicitness of implicit measures. In B. Wittenbrink \& N. Schwarz (Eds.), Implicit measures of attitudes (pp. 179-194). New York: Guilford Press.

Dijksterhuis, A., \& Aarts, H. (2003). On wildebeests and humans: The preferential detection of negative stimuli. Psychological Science, 14, $14-18$.
Epley, N., \& Caruso, E. M. (2004). Egocentric ethics. Social Justice Research, 17, 171-188.

Epley, N., \& Dunning, D. (2000). Feeling "houlier than thou": Are selfserving assessments produced by errors in self- or social prediction? Journal of Personality and Social Psychology, 79, 861-875.

Epley, N., Kaysar, B., Van Boven, L., \& Gilovich, T. (2004). Perspective taking as egocentric anchoring and adjustment. Journal of Personality and Social Psychology, 87, 327-339.

Finkel, N. J. (2001). Not fair! The typology of commonsense unfairness. Washington, DC: American Psychological Association.

Folger, R. (Ed.). (1984). The sense of injustice: Social psychological perspectives. New York: Plenum.

Gilbert, D. T., \& Gill, M. J. (2000). The momentary realist. Psychological Science, 11, 394-398.

Gilovich, T., \& Savitsky, K. (1999). The spotlight effect and the illusion of transparency: Egocentric assessments of how we're seen by others. Current Directions in Psychological Science, 8, 165-168.

Haidt, J. (2001). The emotional dog and its rational tail: A social intuitionist approach to moral judgment. Psychological Review, 108, 814-834

Ham, J. \& Van den Bos, K. (submitted for publication). Automatically inferring the justness of events: Evidence from three implicit measurement paradigms.

Huo, Y. J., Smith, H. J., Tyler, T. R., \& Lind, E. A. (1996). Superordinate identification, subgroup identification, and justice concerns: Is separatism the problem; is assimilation the answer? Psychological Science, 7, 40-45.

Kruger, J. (1999). Lake Wobegon be gone! The "below-average effect" and the egocentric nature of comparative ability judgments. Journal of Personality and Social Psychology, 77, 221-232.

Lind, E. A., \& Tyler, T. R. (1988). The social psychology of procedural justice. New York: Plenum.

Loewenstein, G., Issacharoff, S., Camerer, C., \& Babcock, L. (1993). Selfserving assessments of fairness and pretrial bargaining. Journal of Legal Studies, 22, 135-159.

McKoon, G., \& Ratcliff, R. (1986). Inferences about predictable events. Journal of Experimental Psychology: Learning, Memory, and Cognition, 12, 82-91.

Messick, D. M., \& Sentis, K. (1983). Fairness, preference, and fairness biases. In D. M. Messick \& K. S. Cook (Eds.), Equity theory: Psychological and sociological perspectives (pp. 61-94). New York: Praeger.

Nickerson, R. S. (1999). How we know-and sometimes misjudge-what others know: Imputing one's own knowledge to others. Psychological Bulletin, 125, 737-759.

Ratcliff, R. (1993). Methods for dealing with reaction time outliers. Psychological Bulletin, 114, 510-532.

Ross, L., Green, D., \& House, P. (1977). The "false consensus effect": An egocentric bias in social perception and attribution processes. Journal of Experimental Social Psychology, 13, 279-301.

Uleman, J. S. (1999). Spontaneous versus intentional inferences in impression formation. In S. Chaiken \& Y. Trope (Eds.), Dualprocess theories in social psychology (pp. 141-160). New York: Guilford press.

Uleman, J. S., Hon, A., Roman, R., \& Moskowitz, G. B. (1996). On-line evidence for spontaneous trait inferences at encoding. Personality and Social Psychology Bulletin, 22, 377-394. 